\title{
Antithrombotic drugs do not increase intraoperative blood loss in emergency gastrointestinal surgery: a single-institution propensity score analysis
}

\author{
Tadashi Matsuoka ${ }^{1,2^{*}}$ (D, Kenji Kobayashi ${ }^{1}$, Alan Kawarai Lefor ${ }^{3}$, Junichi Sasaki ${ }^{2}$ and Hiroharu Shinozaki ${ }^{1}$
}

\begin{abstract}
Background: The use of antithrombotic drugs is increasing with the aging population. Prior to elective procedures, antithrombotic drugs are often discontinued. For emergency procedures in patients taking antithrombotic drugs, their effect cannot be attenuated which may lead to an increased risk of hemorrhagic events. However, there are few studies showing increased intraoperative blood loss in patients taking antithrombotic drugs who undergo emergency gastrointestinal surgery. The aim of this study is to determine whether the use of antithrombotic agents increases intraoperative blood loss in emergency gastrointestinal surgery.

Methods: A retrospective review of patients who underwent emergency abdominal surgery between January 2013 and December 2017 was conducted. The primary outcome measure was intraoperative blood loss. Patients were divided into the antithrombotic drug group and a control group, and a propensity score was developed using multivariate logistic regression. We use 1:1 propensity score matching analysis to compare outcomes between the two groups.

Results: Of 1555 patients included in this study, 1184 patients, including 170 patients taking antithrombotic drugs, were eligible for propensity score matching analysis. A 1:1 matching yielded 117 well-balanced pairs. There was no statistically significant difference in intraoperative blood loss (antithrombotic drug group vs control group, median (interquartile): 60 (225-10) vs 100 (243-10) $\mathrm{ml}, p=0.43$ ).

Conclusions: This study suggests that antithrombotic drugs do not increase intraoperative blood loss in patients undergoing emergency gastrointestinal surgery. Emergency gastrointestinal surgery for patients currently taking antithrombotic drugs can be performed safely, and the use of antithrombotic drugs is not a reason to delay surgical intervention.
\end{abstract}

Keywords: Emergency gastrointestinal surgery, Antithrombotic drug, Intraoperative blood loss

\section{Background}

Antithrombotic drugs have important prophylactic and therapeutic effects for patients with various diseases such as coronary artery disease [1], atrial fibrillation [2], cerebrovascular disease [3], and peripheral vascular disease [4]. These beneficial effects have been confirmed in

\footnotetext{
*Correspondence: tadashi_matsuoka1984@yahoo.co.jp

1 Department of Surgery, Saiseikai Utsunomiya Hospital, Tochigi, Japan

²Department of Emergency and Critical Care Medicine, School of Medicine, Keio University, Tokyo, Japan

Full list of author information is available at the end of the article
}

many studies [5-8]. However, these medications can lead to bleeding which is an adverse effect $[9,10]$. They increase the risk of cerebral hemorrhage [10] and gastrointestinal bleeding [11]. There are no agents to rapidly reverse the antithrombotic effects of many of these drugs. Therefore, they are usually stopped prior to the conduct of invasive procedures, such as surgery $[12,13]$ or endoscopic procedures [14-16].

In recent years, the number of patients taking antithrombotic drugs such as antiplatelet agents and anticoagulants is increasing along with the aging population 
[17]. Accordingly, surgeons must manage more patients taking these medications appropriately in the perioperative period. For elective surgery, stopping the antithrombotic drugs is recommended prior to the procedure in many situations [12, 13, 18]. Emergency surgery is often performed under the sustained effects of antithrombotic drugs. Some believe that use of antithrombotic drugs throughout the perioperative period might lead to increased intraoperative blood loss and postoperative bleeding [12-14, 19]. As one notable exception, it was reported that clopidogrel use might not lead to an increased incidence of postoperative bleeding events in abdominal surgery [20]. There is little evidence about the effect of antithrombotic drugs on intraoperative blood loss or the need for blood transfusion. Surgeons have great interest in these effects because they directly relate to intraoperative and postoperative management.

The purpose of this study was to evaluate whether antithrombotic drugs affect intraoperative blood loss in patients undergoing emergency gastrointestinal abdominal surgery. We hypothesized that antithrombotic drugs do not significantly increase intraoperative blood loss. This information is of great importance to surgeons who perform emergency abdominal surgery.

\section{Methods}

\section{Study design}

This retrospective study was approved by the Institutional Review Board of Saiseikai Utsunomiya Hospital (No.201816). Consecutive patients undergoing emergency abdominal surgery from January 2013 to December 2017 at Saiseikai Utsunomiya Hospital in Tochigi, Japan, were included in this study. Emergency gastrointestinal surgery was defined as operations performed within $24 \mathrm{~h}$ of arrival or performed due to deterioration after emergency admission and before planned elective surgery. Patients with traumatic injuries, those undergoing removal of a foreign body, or surgery for post-operative bleeding were excluded. Patients undergoing less frequently performed operations such as liver resection, pancreas resection, or splenectomy were also excluded. After excluding patients undergoing the operations listed above, all emergency gastrointestinal surgery in this study was classified into 1 of 7 types: gastrectomy, patch repair of a duodenal ulcer (e.g., Graham patch), intestinal surgery, colorectal surgery, stoma creation, appendectomy, or cholecystectomy. Clinical and demographic data for included patients were abstracted from the medical records.

\section{Antithrombotic drugs}

Patients taking antiplatelet drugs and/or anticoagulants were classified in the antithrombotic drug group. Antiplatelet drugs included aspirin, clopidogrel, and others. Anticoagulants included warfarin, dabigatran, rivaroxaban, and apixaban. If patients stopped taking the antithrombotic drug before the start of a prescribed cessation period [16], they were considered off the drug. If patients stopped the antithrombotic drug within the prescribed cessation period, they were considered to be taking the drug and classified in the antithrombotic drug group. Patients not taking antithrombotic drugs were classified in the control group.

\section{Outcomes}

The primary outcome of this study was intraoperative blood loss. Intraoperative blood loss was quantified by measuring suction fluid and weighing surgical gauzes used for blood and fluid collection, in which fluid other than blood such as ascites was subtracted. Secondary outcomes were postoperative bleeding and thrombotic events, the need for blood products, mortality, length of hospital stay, and postoperative complications. Bleeding events are defined as bleeding events due to any cause such as surgical site bleeding (superficial, deep, organspace), operative site non-related gastrointestinal tract bleeding, and intracranial bleeding. Thrombotic events are defined as thrombotic events due to any cause such as myocardial infarction/unstable angina pectoris, intracranial infarction/transit ischemic attack, and venous thromboembolism (pulmonary embolism/deep vein thrombosis). The need for blood products is defined as the administration of blood products within the period from the time of surgery until 1 week postoperatively. Severe hemorrhage was defined as intraoperative massive bleeding (blood loss $>750 \mathrm{ml}$ ) or the administration of red blood cells because of intraoperative blood loss.

\section{Statistical analysis \\ Descriptive and bivariate analysis}

All variables are expressed as the median (interquartile range (IQR)) or proportions. Baseline characteristics were compared between the antithrombotic drug group and the control group using the Mann-Whitney $U$ test and Fisher's exact test. Baseline characteristics and antithrombotic drug use were compared between patients with and without severe hemorrhage.

\section{Multivariable logistic regression}

Multivariate analyses were performed using logistic regression to identify independent risk factors for severe bleeding. Logistic regression was also used to determine any association of antithrombotic drug use with severe bleeding after controlling for potential confounders (the independent risk factor for severe bleeding). 


\section{Propensity score matching}

Logistic regression analysis was used to estimate propensity scores to predict the use of antithrombotic drugs from available confounding factors. These factors included age, gender, and surgery type, which were chosen for their potential association with the outcome of interest based on clinical considerations. We did not select comorbidities as confounding factors because the antithrombotic drug group generally has more comorbidities such as coronary artery disease, arrhythmia, or cerebral infarction, which require treatment with antithrombotic drugs. If these comorbidities were set in the propensity score, groups after propensity score matching would be very small and markedly imbalanced. We performed propensity score matching using the following algorithm: 1:1 nearest neighbor matching with no replacement. We used a structured iterative approach to refine this logistic regression model to achieve a balance of covariates within the matched pairs. Standardized differences were used to measure covariate balance, whereby a standardized mean difference (SMD) above $10 \%$ represents a meaningful imbalance. After propensity score matching, the Mann-Whitney $U$ and Fisher's exact tests were used to explore differences in the two groups for continuous variables and categorical variables, respectively.

Differences were considered significant with a $p$ value $<0.05$. All data were analyzed using SPSS 26.0 statistical software (SPSS Inc., Chicago, IL).

\section{Results}

\section{Patient characteristics}

During the study period, 1555 patients underwent emergency gastrointestinal surgery. After applying exclusion criteria (371 patients), 1184 patients remained and were analyzed as an unmatched cohort. Of these, 170 patients (14.4\%) were taking antithrombotic drug at the time of emergency gastrointestinal surgery. Propensity score matching selected 113 patients who used antithrombotic drugs and 113 patients who did not (Fig. 1). Demographic and clinical characteristics before and after propensity score matching and antithrombotic drugs used are shown in Tables 1 and 2. Before matching, patients taking antithrombotic drugs were older and had more comorbidities such as diabetes mellitus, coronary artery disease, and hypertension. There were significant differences in the distribution of the types of surgery. Patients taking antithrombotic drugs were more likely to have undergone intestinal and colorectal surgery, and patients not taking antithrombotic drugs were more likely to have undergone an appendectomy. Laparotomy was more commonly performed for the emergency gastrointestinal procedure on patients taking antithrombotic drugs. After matching, variables such as age, gender, type of surgery, and surgical approach were well balanced between the two groups. The exception was the rate of comorbidities. Since comorbidities were not included in the estimation of the propensity score, there were differences of SMD > 0.1 after matching.

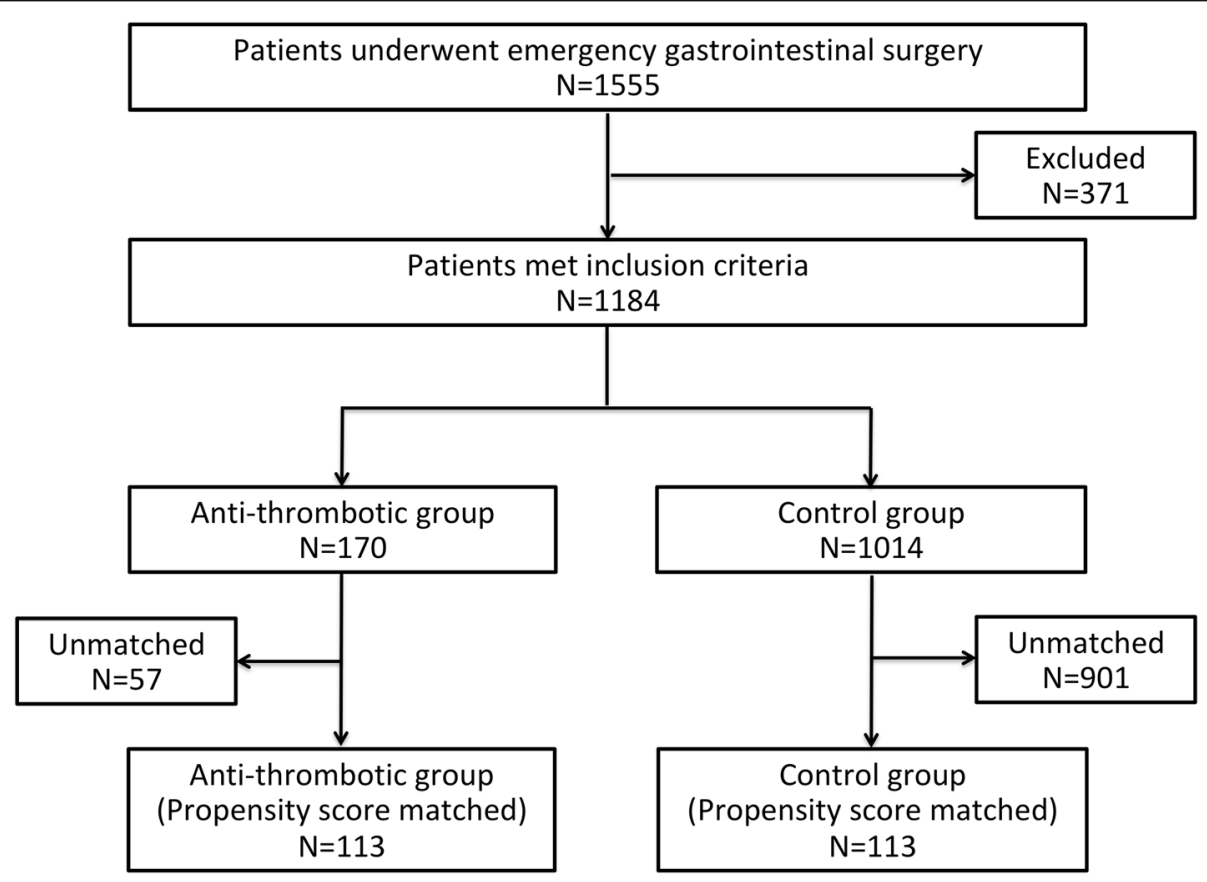

Fig. 1 Study flow chart 
Table 1 Types of antithrombotic drugs and antidotes given

\begin{tabular}{lll}
\hline & Number & $(\%)$ \\
\hline Antithrombotic drugs & 170 & 100 \\
Antiplatelet drugs & 135 & 79 \\
Aspirin & 73 & 43 \\
Clopidogrel & 27 & 16 \\
Other antiplatelet drugs & 47 & 28 \\
Anticoagulant drugs & 42 & 25 \\
Warfarin & 24 & 14 \\
Direct oral anticoagulants & 18 & 11 \\
Antidotes & & 4 \\
Vitamin K & 7 & \\
\hline
\end{tabular}

Table 2 Demographic and clinical characteristics

\begin{tabular}{|c|c|c|c|c|c|c|}
\hline & \multicolumn{3}{|c|}{ Before matching } & \multicolumn{3}{|c|}{ After matching } \\
\hline & AT & Control & SMD & AT & Control & SMD \\
\hline Subjects & 170 & 1014 & & 113 & 113 & \\
\hline Age, years (range) & $79(84-68)$ & $59(73-33)$ & 1.17 & 77 (84-69) & $77(84-69)$ & 0.00 \\
\hline Gender, male & $101(59.4)$ & $573(56.5)$ & 0.04 & $73(64.6)$ & $73(64.6)$ & 0.00 \\
\hline \multicolumn{7}{|l|}{ Type of surgery } \\
\hline Gastrectomy & $1(0.6)$ & $11(1.1)$ & -0.14 & $1(0.9)$ & $1(0.9)$ & 0.00 \\
\hline Patch repair duodenal ulcer & $5(2.9)$ & $56(5.5)$ & -0.05 & $3(2.7)$ & $3(2.7)$ & 0.00 \\
\hline Intestinal surgery & $78(45.9)$ & $252(24.9)$ & -0.13 & $60(53.1)$ & $60(53.1)$ & 0.00 \\
\hline Colorectal surgery & $42(24.7)$ & $129(12.7)$ & 0.45 & $28(24.8)$ & $28(24.8)$ & 0.00 \\
\hline Stoma creation & $18(10.6)$ & $85(8.4)$ & 0.31 & $7(6.2)$ & $7(6.2)$ & 0.00 \\
\hline Appendectomy & $23(13.5)$ & $437(43.1)$ & 0.08 & $13(11.5)$ & $13(11.5)$ & 0.00 \\
\hline Cholecystectomy & $3(1.8)$ & $44(4.3)$ & -0.70 & $1(0.9)$ & $1(0.9)$ & 0.00 \\
\hline \multicolumn{7}{|l|}{ Surgical approach } \\
\hline Laparotomy & $154(90.6)$ & $60(59.5)$ & -0.15 & $103(91.2)$ & $104(92.0)$ & -0.03 \\
\hline Laparoscopy & $16(9.4)$ & $411(40.5)$ & 0.77 & $10(8.8)$ & $9(8.0)$ & 0.03 \\
\hline \multicolumn{7}{|l|}{ Comorbidities } \\
\hline Diabetes mellitus & $43(25.3)$ & $87(8.6)$ & 0.46 & $27(23.9)$ & $21(18.6)$ & 0.13 \\
\hline Renal failure & $21(12.4)$ & $30(3.0)$ & 0.36 & $12(10.6)$ & $4(3.5)$ & 0.3 \\
\hline Liver cirrhosis & $6(3.5)$ & $20(2.0)$ & 0.09 & $3(2.7)$ & $3(2.7)$ & 0.00 \\
\hline Coronary artery disease & $58(34.1)$ & $9(0.9)$ & 0.98 & 36 (31.9) & $2(1.8)$ & 0.88 \\
\hline Atrial fibrillation & 39 (22.9) & $18(1.8)$ & 0.68 & $26(23.0)$ & $5(4.4)$ & 0.57 \\
\hline Cerebrovascular disease & $46(27.1)$ & $11(1.1)$ & 0.81 & $33(29.2)$ & $4(3.5)$ & 0.74 \\
\hline Deep vein thrombosis & $14(8.2)$ & $11(1.1)$ & 0.34 & $9(8.0)$ & $3(2.7)$ & 0.24 \\
\hline Hypertension & $120(70.6)$ & $259(25.5)$ & 1.01 & $79(69.9)$ & $51(45.1)$ & 0.52 \\
\hline Malignancy & $63(37.1)$ & $208(20.5)$ & 0.37 & $35(31.0)$ & $31(27.4)$ & 0.08 \\
\hline
\end{tabular}

\section{Primary outcome}

Before matching, intraoperative blood loss in the antithrombotic drug group was significantly greater than that in the control group (antithrombotic drug group vs control group, median (IQR) $50(210-10)$ ) vs 10 (86-5) $\mathrm{ml}, p<0.001)$. However, after matching, intraoperative blood loss in the antithrombotic drug group was similar to that of the control group (60 (225-10) vs 100 (24310) $\mathrm{ml}, p=0.433$ ) (Fig. 2, Table 3 ).

\section{Secondary outcomes}

Table 3 shows the results of secondary outcomes in this study. Before matching, variables such as the rate and volume of blood transfusions, presence of severe bleeding, mortality, operative time, length of stay, and rate of surgical site infection were higher in the antithrombotic drug group than in the control group. After matching, these variables for the antithrombotic group were similar to those of the control group. Table 4 shows the risk 

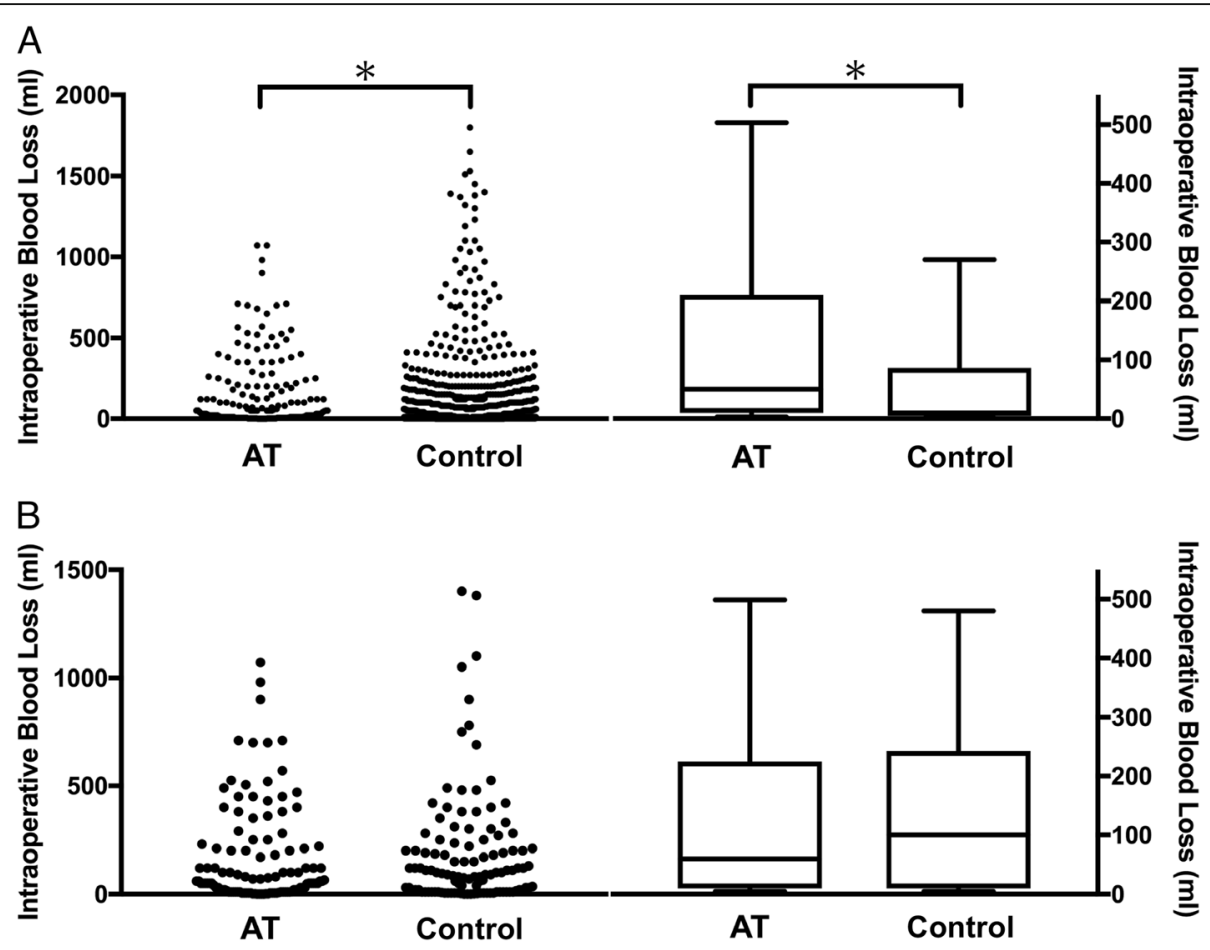

Fig. 2 Comparison of intraoperative blood loss in analysis for antithrombotic drug use (dot plot/box plot). a Before matching. b After matching. ${ }^{*} p<0.05$ compared with the control group as analyzed using Mann-Whitney $U$ test. AT=antithrombotic drug group, Ctrl=control group

factors for severe bleeding, assessed by bivariate analyses. There were significant differences in age (severe bleeding vs non-severe bleeding 77 (84-64) vs 59 (73-33), $p<$ $0.001)$, male $(49.4 \%$ vs $58.0 \%, p=0.037)$, antithrombotic drug use $(19.4 \%$ vs $12.8 \%, p=0.030)$, type of surgery, surgical approach, and comorbidities. As a result of analysis of these variables in the multivariate model, age (per 10 years) (odds ratio (OR) 1.28, 95\% confidence interval (CI) (1.12-1.46)), gastrectomy (OR 6.77, 95\% CI (1.73-26.50)), intestinal surgery (OR $0.43,95 \%$ CI (0.26$0.71)$ ), colorectal resection (OR 1.90, 95\% CI (1.173.10)), appendectomy (OR 0.19, 95\% CI (0.08-0.46)), laparotomy (OR 5.243, 95\% CI (2.23-13.21)), renal failure (OR 2.59, 95\% CI (1.35-4.99)), and malignancy (OR 1.55, 95\% CI (1.05-2.29)) were independent risk factors (Table 5). Antithrombotic drug use was not an independent risk factor (antithrombotic drug (OR 0.73, 95\% CI (0.45-1.17), $p=0.193$ ), antiplatelet drugs (OR 0.71, 95\% CI (0.42-1.21), $p=0.204)$, anticoagulant drugs (OR 1.29 , 95\% CI (0.61-2.71), $p=0.508)$, and dual antithrombotic drugs (OR $0.66,95 \%$ CI $(0.21-2.10), p=0.480)$ ).

In the analysis of antiplatelet drugs and dual antithrombotic drugs, as well as the analysis of antithrombotic drug use, although patients in the antiplatelet drug group and dual antithrombotic drug group had more intraoperative blood loss than the control group before matching, the median blood loss in these groups was not statistically significantly different from the control group after matching (Additional file 1 (A, B), Additional file 2 (A, B), Additional file 3, and Additional file 4)

\section{Discussion}

This study suggests that antithrombotic drugs have no significant effect on the volume of intraoperative blood loss in emergency gastrointestinal surgery after adjustment for confounding factors by propensity score matching. To the best of our knowledge, this is the first report to evaluate the relationship between antithrombotic drug use and intraoperative blood loss in patients undergoing emergency gastrointestinal surgery.

Increase of intraoperative blood loss confers unfavorable effects on immune function [21-23] and is associated with major complications or a worse prognosis in patients undergoing a variety of operations $[24,25]$. Other studies reported that more intraoperative blood loss induces suppression of anti-tumor effects, microscopic spillage of cancer cells in the blood resulting in a worse prognosis in patients undergoing surgery for cancer $[21,26,27]$. These studies support the idea that a decrease in unnecessary bleeding results in less harm to patients undergoing gastrointestinal surgery. Patients currently taking antithrombotic drugs may be thought to have increased bleeding tendencies. Based on the results of this study, surgeons do not need to hesitate to perform surgery in these patients. 
Table 3 Primary and secondary outcomes

\begin{tabular}{|c|c|c|c|c|c|c|}
\hline & \multicolumn{3}{|c|}{ Before matching } & \multicolumn{3}{|c|}{ After matching } \\
\hline & AT & Control & $p$ value & $\overline{\text { AT }}$ & Control & $p$ value \\
\hline Subjects & 170 & 1014 & & 113 & 113 & \\
\hline Intraoperative blood loss (ml) & $50(210-10)$ & $10(86-5)$ & $<0.001$ & $60(225-10)$ & $100(243-10)$ & 0.433 \\
\hline Severe hemorrhage & $33(19.4)$ & $137(13.5)$ & 0.03 & $25(22.1)$ & $22(19.5)$ & 0.743 \\
\hline \multicolumn{7}{|l|}{ Blood transfusion } \\
\hline Red Blood Cell & $36(21.2)$ & $123(12.1)$ & 0.002 & $27(23.9)$ & $18(15.9)$ & 0.182 \\
\hline Amount (units) & $0(0-0)$ & $0(0-0)$ & 0.002 & $0(0-0)$ & $0(0-0)$ & 0.127 \\
\hline Fresh Frozen Plasma & $30(17.6)$ & $74(7.3)$ & $<0.001$ & $19(16.8)$ & $15(13.3)$ & 0.577 \\
\hline Amount (units) & $0(0-0)$ & $0(0-0)$ & $<0.001$ & $0(0-0)$ & $0(0-0)$ & 0.430 \\
\hline Platelet & $8(4.7)$ & $22(2.2)$ & 0.063 & $7(6.2)$ & $2(1.8)$ & 0.171 \\
\hline Amount (units) & $0(0-0)$ & $0(0-0)$ & 0.051 & $0(0-0)$ & $0(0-0)$ & 0.090 \\
\hline Bleeding events & $7(4.1)$ & $25(2.5)$ & 0.206 & $5(4.4)$ & $2(1.8)$ & 0.446 \\
\hline Thrombotic events & $4(2.4)$ & $21(2.1)$ & 0.773 & $2(1.8)$ & $3(2.7)$ & 1.000 \\
\hline Mortality & $16(9.4)$ & $35(3.5)$ & 0.001 & $11(9.7)$ & $5(4.4)$ & 0.193 \\
\hline Operative time (min) & $101(149-73)$ & $90(127-65)$ & $<0.001$ & $99(150-72)$ & $117(151-77)$ & 0.244 \\
\hline Length of stay (days) & $21(33-13)$ & $6(19-10)$ & $<0.001$ & $21(33-13)$ & $16(29-11)$ & 0.060 \\
\hline \multicolumn{7}{|l|}{ Other complications } \\
\hline Surgical site infection & $33(19.4)$ & $133(13.1)$ & 0.032 & $26(23.0)$ & $29(25.7)$ & 0.757 \\
\hline Abscess & $20(11.8)$ & $112(11.0)$ & 0.792 & $14(12.4)$ & $18(15.9)$ & 0.568 \\
\hline Pneumonia & $21(12.4)$ & $43(4.2)$ & $<0.001$ & 15 (13.3) & $9(8.0)$ & 0.280 \\
\hline
\end{tabular}

Data are presented as number (percentage) or median (interquartile)

One unit of red blood cells, fresh frozen plasma, and platelet are approximately $120 \mathrm{cc}, 120 \mathrm{cc}$, and $20 \mathrm{cc}$, respectively

$A T$ antithrombotic drug group

Before matching, patients using antithrombotic drugs had more intraoperative blood loss, higher rate of blood transfusions, higher mortality, longer hospital stay, and a higher rate of surgical site infections than patients not taking antithrombotic drugs. However, after adjustment for confounding factors, the outcomes were comparable between the two groups, with no significant differences. Patients taking antiplatelet drugs alone and those taking dual antithrombotic drugs had results similar to results for patients taking antithrombotic drugs. In multivariate analysis, the use of antithrombotic drugs, including antiplatelet drugs and dual antithrombotic drugs, was not an independent risk factor for severe bleeding. These results suggest that age and the type of surgery are related to intraoperative blood loss and other outcomes, but antithrombotic drug use is not related. The use of antithrombotic drugs alone does not seem to increase the risk of intraoperative blood loss, postoperative bleeding, or thrombotic events.

In the guidelines for gastroenterological endoscopy in patients currently receiving antithrombotic treatment $[15,16]$, withdrawal of aspirin monotherapy is not required for patients who would be placed at high risk of thromboembolism by cessation. It is recommended that in patients with a low risk of thromboembolism, aspirin can be withdrawn for 3 to 5 days $[15,16]$. In elective general and abdominal surgery for patients not at high risk of cardiovascular events, Antolovic et al. reported that continuation of an antiplatelet drug did not influence the incidence of severe bleeding [28]. There was no difference in intraoperative blood loss, postoperative anemia, or blood transfusion requirement for patients with and without aspirin therapy undergoing laparoscopic cholecystectomy [29]. While some studies reviewed very specific patient, disease, or surgery types, there are few evidence-based studies of the relationship between antithrombotic drugs and emergency gastrointestinal surgery reviewing a wide range of patients and diseases. Recently, Jupiter et al. reported the relationship between clopidogrel use and postoperative bleeding [20]. These investigators concluded that clopidogrel use slightly increases postoperative bleeding events statistically, but has no significant clinical effect. At the time of that study, whether antithrombotic drugs actually increase intraoperative blood loss or postoperative thrombotic events had not been shown. This led to difficulties in assessing the risk of increased intraoperative blood loss or the need for blood transfusions in emergency gastrointestinal surgery for patients taking antithrombotic drugs. The present study suggests that antithrombotic drugs do not increase intraoperative blood loss, 
Table 4 Bivariate analyses of severe bleeding

\begin{tabular}{|c|c|c|c|}
\hline & Severe bleeding & Non severe bleeding & $p$ value \\
\hline Subjects & 170 & 1014 & \\
\hline Age, years (range) & 77 (84-64) & $59(73-33)$ & $<0.001$ \\
\hline Gender, male & $84(49.4)$ & $588(58.0)$ & 0.037 \\
\hline Antithrombotic drugs & $33(19.4)$ & $130(12.8)$ & 0.030 \\
\hline Antiplatelet drugs & $23(13.5)$ & 105 (10.4) & 0.230 \\
\hline Anticoagulant drugs & $14(8.2)$ & $28(2.8)$ & 0.001 \\
\hline Dual antithrombotic drugs & $4(2.4)$ & $22(2.2)$ & 0.781 \\
\hline \multicolumn{4}{|l|}{ Type of surgery } \\
\hline Gastrectomy & $9(5.3)$ & $3(0.3)$ & $<0.001$ \\
\hline Patch repair duodenal ulcer & $7(4.1)$ & $54(5.3)$ & 0.707 \\
\hline Intestinal surgery & $43(25.3)$ & $285(28.1)$ & 0.461 \\
\hline Colorectal surgery & $67(39.4)$ & $104(10.3)$ & $<0.001$ \\
\hline Stoma formation & $30(17.6)$ & $73(7.2)$ & $<0.001$ \\
\hline Appendectomy & $7(4.1)$ & $453(44.7)$ & $<0.001$ \\
\hline Cholecystectomy & $7(4.1)$ & $40(3.9)$ & 0.834 \\
\hline Surgical approach & & & $<0.001$ \\
\hline Laparotomy & $164(96.5)$ & $591(58.3)$ & \\
\hline Laparoscopy & $6(3.5)$ & $423(41.7)$ & \\
\hline \multicolumn{4}{|l|}{ Comorbidities } \\
\hline Diabetes mellitus & $36(21.2)$ & $94(9.3 .6)$ & $<0.001$ \\
\hline Renal failure & $20(11.8)$ & $30(3.0)$ & $<0.001$ \\
\hline Liver cirrhosis & $11(6.5)$ & $15(1.5)$ & $<0.001$ \\
\hline Coronary artery disease & $10(5.9)$ & $55(5.4)$ & 0.855 \\
\hline Atrial fibrillation & $20(11.8)$ & $36(3.6)$ & $<0.001$ \\
\hline Cerebrovascular disease & $14(8.2)$ & $43(4.2)$ & 0.032 \\
\hline Deep vein thrombosis & $7(4.1)$ & $18(1.8)$ & 0.075 \\
\hline Hypertension & $97(57.1)$ & $280(27.6)$ & $<0.001$ \\
\hline Malignancy & $79(46.5)$ & 192 (18.9) & $<0.001$ \\
\hline \multicolumn{4}{|l|}{ Blood transfusion } \\
\hline Red Blood Cell & $159(93.5)$ & $0(0.0)$ & $<0.001$ \\
\hline Amount (units) & $4(2-6)$ & $0(0-0)$ & $<0.001$ \\
\hline Fresh frozen plasma & $81(47.6)$ & $24(2.4)$ & $<0.001$ \\
\hline Amount (units) & $0(10-0)$ & $0(0-0)$ & $<0.001$ \\
\hline Platelet & $27(15.9)$ & $4(0.4)$ & $<0.001$ \\
\hline Amount (units) & $0(0-0)$ & $0(0-0)$ & $<0.001$ \\
\hline Bleeding events & $21(12.4)$ & $12(1.2)$ & $<0.001$ \\
\hline Thrombotic events & $9(5.3)$ & $16(1.6)$ & 0.006 \\
\hline Mortality & $36(21.2)$ & $14(1.4)$ & $<0.001$ \\
\hline Operative time (min) & $136(183-100)$ & $86(121-63)$ & $<0.001$ \\
\hline Length of stay (days) & $31(53-17)$ & $10(18-5)$ & $<0.001$ \\
\hline \multicolumn{4}{|l|}{ Other complications } \\
\hline Surgical site infection & $57(33.5)$ & $108(10.7)$ & $<0.001$ \\
\hline Abscess & $50(29.4)$ & $81(8.0)$ & $<0.001$ \\
\hline Pneumonia & 35 (20.6) & $28(2.8)$ & $<0.001$ \\
\hline
\end{tabular}

Data are presented as number (percentage) or median (interquartile). One unit of red blood cells, fresh frozen plasma, and platelet are approximately $120 \mathrm{cc}, 120 \mathrm{cc}$, and $20 \mathrm{cc}$, respectively 
Table 5 Multivariate analysis of severe bleeding

\begin{tabular}{|c|c|c|c|c|c|}
\hline \multirow[b]{2}{*}{ Age (per 10 years) } & \multirow{2}{*}{$\begin{array}{l}\text { Coefficient } \\
0.24\end{array}$} & \multirow{2}{*}{$\begin{array}{l}p \text { value } \\
<0.001\end{array}$} & \multirow{2}{*}{$\begin{array}{l}\text { Odds ratio } \\
1.28\end{array}$} & \multicolumn{2}{|c|}{ 95\% confidential interval } \\
\hline & & & & 1.12 & 1.46 \\
\hline Gastrectomy & 1.91 & 0.006 & 6.77 & 1.73 & 26.50 \\
\hline Intestinal surgery & -0.85 & 0.001 & 0.43 & 0.26 & 0.71 \\
\hline Colorectal surgery & 0.64 & 0.010 & 1.90 & 1.17 & 3.10 \\
\hline Appendectomy & -1.65 & $<0.001$ & 0.19 & 0.08 & 0.46 \\
\hline Laparotomy & 1.69 & $<0.001$ & 5.43 & 2.23 & 13.21 \\
\hline Renal failure & 0.95 & 0.004 & 2.59 & 1.35 & 4.99 \\
\hline Malignancy & 0.44 & 0.029 & 1.55 & 1.05 & 2.29 \\
\hline Antithrombotic drug & -0.32 & 0.193 & 0.73 & 0.45 & 1.17 \\
\hline Antiplatelet drug & -0.34 & 0.204 & 0.71 & 0.42 & 1.21 \\
\hline Anticoagulant drug & 0.25 & 0.508 & 1.29 & 0.61 & 2.71 \\
\hline Dual antithrombotic drug & -0.42 & 0.480 & 0.66 & 0.21 & 2.10 \\
\hline
\end{tabular}

$x^{2}<0.001$, AUC $=0.840(0.813-0.868)$, percentage correct $86.6 \%$

need for blood transfusion, or postoperative bleeding and thrombotic events. Since the perioperative risk for patients undergoing emergency surgery is higher than patients undergoing elective surgery, these results may apply to elective procedures as well but further study is needed.

This study has acknowledged limitations. First, although propensity score matching is used to decrease the bias between the two groups, this study is retrospective. Propensity score matching cannot equalize unmeasured confounding factors, so there might be residual confounders affecting these results. There are some differences in comorbidities between the two groups after propensity matching. Therefore, unmeasured confounding factors and differences in comorbidities may affect these results. Second, the study is not blinded. With the information regarding antithrombotic drug use, surgeons may be especially careful with the management of blood loss. Third, the use of antidotes and the timing of restarting antithrombotic drugs were left to the discretion of each attending surgeon. Vitamin $\mathrm{K}$, which needs time to normalize the PT-INR, was given only to a few patients, and if vitamin $\mathrm{K}$ was given, it would likely not be effective as an antidote during the operation. Therefore, we think the effect of vitamin $\mathrm{K}$ on the results of this study is minimal. Surgeons tend to restart antithrombotic drugs when they believe the risk of postoperative bleeding has subsided. Without a uniform standard for postoperative resumption of antithrombotic drugs, there is variation. Fourth, because the sample size became small due to propensity score matching, we might not have been able to find a significant difference in this study. Fifth, because the effect of combinations of antithrombotic drugs and the type of surgery were not analyzed, the heterogeneity of antithrombotic drugs given and type of surgery might affect the results. Finally, the judgment to perform the operation and the choice of procedure depends on each surgeon. For a patient taking antithrombotic drugs with a high risk of bleeding, surgeons might choose a less invasive procedure, or nonoperative therapy, which they would not choose if the patient did not use antithrombotic drugs.

\section{Conclusion}

This study suggests that antithrombotic drugs do not significantly affect intraoperative blood loss in patients undergoing emergency gastrointestinal surgery. These findings should improve the approach to patients taking antithrombotic drug, who need emergency gastrointestinal surgery. A large-scale retrospective study or a prospective randomized controlled trial is required to confirm these findings.

\section{Supplementary information}

Supplementary information accompanies this paper at https://doi.org/10. 1186/s13017-019-0284-8.

Additional file 1. Comparison of intraoperative blood loss in analysis for antiplatelet drug use (dot plot / box plot). (A) before matching, (B) after matching. Description: * $P<0.05$ compared with the control group as analyzed Mann Whitney $U$ test. $A P=$ antiplatelet drug group, Ctrl=control group.

Additional file 2. Comparison of intraoperative blood loss in analysis for dual antithrombotic drug use (dot plot / box plot). (A) before matching, (B) after matching. Description: DAT=antithrombotic drug group

Additional file 3. Demographic and Clinical Characteristics for antiplatelet drug analysis. Description: Data are presented as number (percentage) or median (interquartile). $\mathrm{AP}=$ antiplatelet drug group; $\mathrm{SMD}=$ standardized mean difference.

Additional file 4. Demographic and Clinical Characteristics for dual antithrombotic drug analysis. Description: Data are presented as number (percentage) or median (interquartile). DAT=dual antithrombotic drug group; SMD=standardized mean difference. 


\section{Abbreviations}

Cl: Confidence interval; IQR: Interquartile range; OR: Odds ratio; SMD: Standardized mean difference

\section{Acknowledgements}

Not applicable.

\section{Authors' contributions}

TM contributed to this manuscript through study design, data collection, data analysis and interpretation, and manuscript writing. HS contributed to the study design and data interpretation. AL contributed to the data interpretation and critical revisions of the manuscript. KK and JS were involved in study design, data interpretation, and manuscript review. All authors read and approved the final manuscript.

\section{Funding}

Not applicable.

\section{Availability of data and materials}

The datasets used and/or analyzed during the current study are available from the corresponding author on reasonable request.

\section{Ethics approval and consent to participate}

This study was approved by the Institutional Review Board of Saiseikai Utsunomiya Hospital (No.2018-16). The requirement for obtaining informed consent from patients was waived because the data sets were pseudonymous and this study was observational.

\section{Consent for publication}

Informed consent was waived because of the anonymous nature of the data.

\section{Competing interests}

The authors declare that they have no competing interests.

\section{Author details}

'Department of Surgery, Saiseikai Utsunomiya Hospital, Tochigi, Japan. 2Department of Emergency and Critical Care Medicine, School of Medicine, Keio University, Tokyo, Japan. ${ }^{3}$ Department of Surgery, Jichi Medical University, Tochigi, Japan.

Received: 14 November 2019 Accepted: 18 December 2019

Published online: 30 December 2019

\section{References}

1. Arnett DK, Blumenthal RS, Albert MA, Buroker AB, Goldberger ZD, Hahn EJ, et al. 2019 ACC/AHA guideline on the primary prevention of cardiovascular disease: executive summary: a report of the American College of Cardiology/American Heart Association Task Force on Clinical Practice Guidelines. Circulation. 2019;140:e563-e95.

2. Kirchhof P, Benussi S, Kotecha D, Ahlsson A, Atar D, Casadei B, et al. 2016 ESC Guidelines for the management of atrial fibrillation developed in collaboration with EACTS. Eur Heart J. 2016;37:2893-962.

3. Kernan WN, Ovbiagele B, Black HR, Bravata DM, Chimowitz MI, Ezekowitz $M D$, et al. Guidelines for the prevention of stroke in patients with stroke and transient ischemic attack: a guideline for healthcare professionals from the American Heart Association/American Stroke Association. Stroke. 2014; 45:2160-236.

4. Gerhard-Herman MD, Gornik HL, Barrett C, Barshes NR, Corriere MA, Drachman DE, et al. 2016 AHA/ACC guideline on the management of patients with lower extremity peripheral artery disease: a report of the American College of Cardiology/American Heart Association Task Force on Clinical Practice Guidelines. Circulation. 2017;135:e726-e79.

5. Antithrombotic Trialists C. Collaborative meta-analysis of randomised trials of antiplatelet therapy for prevention of death, myocardial infarction, and stroke in high risk patients. BMJ. 2002;324:71-86

6. Lopes RD, Hong H, Harskamp RE, Bhatt DL, Mehran R, Cannon CP, et al, Safety and efficacy of antithrombotic strategies in patients with atrial fibrillation undergoing percutaneous coronary intervention: a network meta-analysis of randomized controlled trials. JAMA Cardiol. 2019.
7. Niu PP, Guo ZN, Jin H, Xing YQ, Yang Y. Antiplatelet regimens in the longterm secondary prevention of transient ischaemic attack and ischaemic stroke: an updated network meta-analysis. BMJ Open. 2016;6:e009013.

8. Fleisher LA, Fleischmann KE, Auerbach AD, Barnason SA, Beckman JA, Bozkurt B, et al. 2014 ACC/AHA guideline on perioperative cardiovascular evaluation and management of patients undergoing noncardiac surgery: executive summary: a report of the American College of Cardiology/ American Heart Association Task Force on Practice Guidelines. Circulation. 2014:130:2215-45

9. Li L, Geraghty OC, Mehta Z, Rothwell PM, Oxford Vascular S. Age-specific risks, severity, time course, and outcome of bleeding on long-term antiplatelet treatment after vascular events: a population-based cohort study. Lancet. 2017:390:490-9.

10. Flaherty ML, Kissela B, Woo D, Kleindorfer D, Alwell K, Sekar P, et al. The increasing incidence of anticoagulant-associated intracerebral hemorrhage. Neurology. 2007;68:116-21

11. MCQuaid KR, Laine L. Systematic review and meta-analysis of adverse events of low-dose aspirin and clopidogrel in randomized controlled trials. Am J Med. 2006:119:624-38.

12. American Society of Anesthesiologists Task Force on Perioperative Blood M. Practice guidelines for perioperative blood management: an updated report by the American Society of Anesthesiologists Task Force on Perioperative Blood Management*. Anesthesiology. 2015;122:241-75.

13. Ferraris VA, Saha SP, Oestreich JH, Song HK, Rosengart T, Reece TB, et al. 2012 update to the Society of Thoracic Surgeons guideline on use of antiplatelet drugs in patients having cardiac and noncardiac operations. Ann Thorac Surg. 2012;94:1761-81.

14. The Society of American Gastrointestinal and Endoscopic Surgeons Guidelines Committee, Anderson MA, Ben-Menachem T, Gan SI, Appalaneni $\mathrm{V}$, Banerjee $\mathrm{S}$, et al. Management of antithrombotic agents for endoscopic procedures. Gastrointest Endosc. 2009;70:1060-70.

15. Chan FKL, Goh KL, Reddy N, Fujimoto K, Ho KY, Hokimoto S, et al. Management of patients on antithrombotic agents undergoing emergency and elective endoscopy: joint Asian Pacific Association of Gastroenterology (APAGE) and Asian Pacific Society for Digestive Endoscopy (APSDE) practice guidelines. Gut. 2018;67:405-17.

16. Fujimoto K, Fujishiro M, Kato M, Higuchi K, Iwakiri R, Sakamoto C, et al. Guidelines for gastroenterological endoscopy in patients undergoing antithrombotic treatment. Dig Endosc. 2014;26:1-14.

17. Ohman EM, Bhatt DL, Steg PG, Goto S, Hirsch AT, Liau CS, et al. The REduction of Atherothrombosis for Continued Health (REACH) Registry: an international, prospective, observational investigation in subjects at risk for atherothrombotic events-study design. Am Heart J. 2006;151:786 e1-10.

18. Burger W, Chemnitius JM, Kneissl GD, Rucker G. Low-dose aspirin for secondary cardiovascular prevention - cardiovascular risks after its perioperative withdrawal versus bleeding risks with its continuation - review and meta-analysis. J Intern Med. 2005;257:399-414.

19. Society of Thoracic Surgeons Blood Conservation Guideline Task F, Ferraris VA, Brown JR, Despotis GJ, Hammon JW, Reece TB, et al. 2011 update to the Society of Thoracic Surgeons and the Society of Cardiovascular Anesthesiologists blood conservation clinical practice guidelines. Ann Thorac Surg. 2011;91:944-82.

20. Jupiter DC, Fang X, Adhikari D, Mehta HB, Riall TS. Safety of continued clopidogrel use in the preoperative course of gastrointestinal surgery: a retrospective cohort study. Ann Surg. 2017:265:370-8.

21. Dhar DK, Kubota H, Tachibana M, Kotoh T, Tabara H, Watanabe R, et al. Long-term survival of transmural advanced gastric carcinoma following curative resection: multivariate analysis of prognostic factors. World I Surg. 2000;24:588-93 discussion 93-4.

22. Liang $Y X$, Guo HH, Deng JY, Wang BG, Ding XW, Wang XN, et al. Impact of intraoperative blood loss on survival after curative resection for gastric cancer. World J Gastroenterol. 2013;19:5542-50.

23. Bruns $\mathrm{CJ}$, Schafer $\mathrm{H}$, Wolfgarten B, Engert A. Effect of intraoperative blood loss on the function of natural killer cells in tumors of the upper gastrointestinal tract. Langenbecks Arch Chir Suppl Kongressbd. 1996;113:146-9.

24. Ejaz A, Gani F. Frank SM, Pawlik TM. Improvement of the surgical Apgar score by addition of intraoperative blood transfusion among patients undergoing major gastrointestinal surgery. J Gastrointest Surg. 2016;20: 1752-9.

25. Mizuno A, Kanda M, Kobayashi D, Tanaka C, Iwata N, Yamada S, et al. Adverse effects of intraoperative blood loss on long-term outcomes after 
curative gastrectomy of patients with stage II/III gastric cancer. Dig Surg. 2016;33:121-8.

26. Ito $Y$, Kanda $M$, Ito $S$, Mochizuki $Y$, Teramoto $H$, Ishigure $K$, et al. Intraoperative blood loss is associated with shortened postoperative survival of patients with stage I//III gastric cancer: analysis of a multi-institutional dataset. World J Surg. 2019:43:870-7.

27. Ishino Y, Saigusa S, Ohi M, Yasuda H, Tanaka K, Toiyama Y, et al. Preoperative C-reactive protein and operative blood loss predict poor prognosis in patients with gastric cancer after laparoscopy-assisted gastrectomy. Asian J Endosc Surg. 2014;7:287-94.

28. Antolovic D, Rakow A, Contin P, Ulrich A, Rahbari NN, Buchler MW, et al. A randomised controlled pilot trial to evaluate and optimize the use of antiplatelet agents in the perioperative management in patients undergoing general and abdominal surgery-the APAP trial (ISRCTN45810007). Langenbeck's Arch Surg. 2012;397:297-306.

29. Joseph B, Rawashdeh B, Aziz H, Kulvatunyou N, Pandit V, Jehangir Q, et al. An acute care surgery dilemma: emergent laparoscopic cholecystectomy in patients on aspirin therapy. Am J Surg. 2015;209:689-94.

\section{Publisher's Note}

Springer Nature remains neutral with regard to jurisdictional claims in published maps and institutional affiliations.

- fast, convenient online submission

- thorough peer review by experienced researchers in your field

- rapid publication on acceptance

- support for research data, including large and complex data types

- gold Open Access which fosters wider collaboration and increased citations

- maximum visibility for your research: over $100 \mathrm{M}$ website views per year

At $\mathrm{BMC}$, research is always in progress. 